Journal of Social Sciences 8 (1): 109-115, 2012

ISSN 1549-3652

(C) 2012 Science Publications

\title{
From “Foreign" Language Education to Plurilingualism: Challenges for Language Education Policy in a Multilingual Japan
}

\author{
Teja Ostheider \\ School of Law and Politics, Kwansei Gakuin University, \\ 1-155 Uegahara Ichiban-Cho, Nishinomiya 662-8501, Japan
}

\begin{abstract}
Problem statement: With a $41 \%$ increase in foreign residents over the last 10 years, the long-neglected issue of domestic multiculturalism and multilingualism cannot be ignored anymore in Japan. Nevertheless, there is still a deep gap between common images created by mass media and education regarding "internationalization" or "globalization" and the actual condition of Japan as a migrant country. By discussing the sociological background of this gap and its sociolinguistic consequences, this study points out present problems and challenges regarding language education policies in Japan. Approach: Based on data out of field-work, I analyze language attitudes derived from a language education which is mainly restricted to the "National Language" and English and discuss their impact on actual language behavior towards different groups of Non-Japanese people in Japan. Results: The data shows that "communication with foreigners" in Japan is widely associated with the use of English. However, the respondents reported communicating primarily in English only with people from Western countries, while with people from Asian countries-who make up the vast majority of foreign residents in Japan-Japanese is the primarily used language. Besides common images and stereotypes regarding "foreigner" and "foreign language", different attitudes and experiences concerning communication with these two groups were found as significant factors in this contradiction. Conclusion: I summarize by pointing out the necessity of a more objective education and awareness regarding the multilingual and multicultural situation in Japan. The inclusion of languages of domestic minorities and neighboring countries in education policies is an important step to abolish stereotypes and linguistic discrimination based on one-sided orientation towards the West and myths about Japanese homogeneity. Concerning the Japanese language itself, I discuss its growing importance for intercultural communication and emphasize the necessity of education policies fostering native speakers' ability in "Japanese as an international language".
\end{abstract}

Key words: Minority languages, migrant languages, language attitudes, intercultural communication

\section{INTRODUCTION}

Japan is without doubt a multilingual nation. Not only the languages of domestic minorities like Ryukyuan, Ainu, Korean or the Japanese Sign Language, also the languages of the rising number of migrants to the country make Japan a multilingual society. In sharp contrast to this fact are the country's language education policies, which are mainly restricted to two languages: The "National Language" (Japanese, the only official language in Japan) and English. It is beyond saying that language attitudes shaped by these policies are also rather simple: Japan is commonly considered a monolingual nation and Japanese a language exclusive to the Japanese people, while other languages are regarded as "foreign" and English is believed to be understood all over the world and thus indispensable for all human beings.
The "National Language" is the only domestic language that is subject of compulsory education. Here it seems that little has changed since its creation in the Meiji era and the long history of assimilating language policies, which forced minorities like the Ainu or Ryukyuan people and migrants from former colonies to commit linguistic suicide. The second language that is subject of compulsory education is English. Policies like the "Establishment of an Action Plan to Cultivate 'Japanese with English Abilities"' by the Ministry of Education, Culture, Sports, Science and Technology (MEXT) MEXT, 2002 illustrate how much attention this language attracts. Connected with buzzwords such as Japan's "internationalization" or, more recently, "globalization", English commonly stands for "foreign language" in general. But being realistic, one must realize that a second language education that is restricted to English fails to meet the actual needs inside the country. First, the overwhelming majority of 
foreign residents in Japan are from Asian or South American countries and second, compared to the amount of time and effort invested in English language education, the actual need of English for the average Japanese person in everyday life is relatively low. Here the cultivation of native speakers' abilities in Japanese as a language of intercultural communication should be a more urgent task for language policies focusing on "internationalization". Another problem posed by English being the sole counterpart to the "National Language" in compulsory education is the fact that in the Japanese context English commonly symbolizes "foreignness" and hence plays an important role in maintaining existing myths of domestic homogeneity.

A similar tendency can be observed regarding the so called "second foreign" language education, which is not compulsory and thus for the general student does not apply before university. Here it has to be criticized that in modern times European languages such as German or French have been receiving much more attention than languages of neighboring countries or domestic minorities. From this point of view it is rather interesting that, as a reaction to the threats of English language imperialism, especially instructors of these European languages recently started emphasizing the importance of their languages by referring to the European concept of "Plurilingualism"- often ignoring the fact that this concept has to be understood in reference to languages which are actually used in the environment of the learner.

Even though it is not aware of it, Japan is a migrant country. There are more than 2 million residents of foreign nationality living in the country - amongst them about 130,000 children at school age. It goes without saying that education and language policies have to be considered an essential part of immigration policies. Regrettably, in Japan immigration policy does merely mean "immigration control". The only government authority responsible for immigration policies is the Immigration Bureau of the Ministry of Justice and there is no authority for social integration. One of the severe consequences is the fact that education is not compulsory for children of foreign nationality in Japan. There are alarming statistics for example from the year 2000, reporting that amongst 17,000 Brazilian children at school age 7,000 were not attending school (Sugino, 2007). According to the Ministry of Education MEXT, 2009, amongst those children attending public schools in 2009 about 30,000 were in "need of Japanese language instruction", their first languages being mainly Portuguese (40\%), Chinese (20\%), Spanish (13\%) and Filipino (12\%). Not only concerning the "National Language" and English, also in reference to "second foreign" languages, these numbers illustrate once more the need for more realistic and adequate language education policies in Japan.

\section{MATERIALS AND METHODS}

By discussing the above mentioned situation of language education in Japan and giving concrete examples of its impact on language attitudes and actual language behavior towards different groups of NonJapanese people in Japan, this study attempts to point out some possibilities and challenges for language education policy in contemporary Japan. Concerning empirical research, I refer to data out of a field-work survey conducted with 220 Japanese nationals in Kyoto and Osaka in 1997 (Survey A) and questionnaires conducted with 378 Japanese university students at two Japanese universities during the years 2006-2010 (Survey B).

Survey A investigated Japanese native speakers' experiences and views regarding communication with different groups of foreigners as well as their attitudes concerning language choice and the Japanese language itself. The survey was based on oral interviews and written questionnaires conducted with respondents from different age-groups (Table 1). In some parts of the analysis of the survey the distinction between "Asian" and "Western" foreigners was employed in accordance to common interpretations amongst Japanese people regarding these two groups; i.e., "Asian" refers to people from East- and Southeast-Asia and "Western" to white, "Caucasian" people, especially from North America, Europe and Oceania. This very broad distinction was made intentionally to compare experiences and views particularly towards these two groups-the former for making up the majority of foreign residents in Japan and the latter for being a very small minority that attracts the majority of attention.

Survey B was conducted as a part of seven lectures the author held on multilingualism and language policy at Kinki University in Osaka (2006-2007) and Kwansei Gakuin University in Nishinomiya (2008-2010). The respondents are first, second and third grade students of both sexes (The data discussed in this study does not include the answers of students with a NonJapanese background).

\begin{tabular}{llllll}
\multicolumn{6}{l}{ Table 1: Respondents of survey A } \\
\hline Age & $\begin{array}{l}16-18 \\
\text { (high-school) }\end{array}$ & $\begin{array}{l}19-22 \\
\text { (university) }\end{array}$ & $23-40$ & $41-60$ & above 60 \\
\hline Male & 20 & 20 & 30 & 20 & 20 \\
Female & 20 & 20 & 30 & 20 & 20 \\
\hline
\end{tabular}




\section{J. Social Sci., 8 (1): 109-115, 2012}

At the beginning of each semester the author asked the participants to fill in short questionnaires in order to obtain data on their views and attitudes, which was then discussed in the further course of the lecture. The questionnaires focused on the students' views and general knowledge about foreign residents in Japan and their attitudes concerning the Japanese language as well as the acquisition and usage of other languages. Regarding language attitudes, some of the questions of Survey B were adopted from Survey A in order to compare the data and to reconfirm or revise the results of Survey A, which was conducted 10 years earlier.

\section{RESULTS}

In one question of Survey B, 378 Japanese university students were asked to guess the three most frequent nationalities of foreign residents living in Japan. As a result, 258 students (an average of 2 out of 3) ranked the USA among the top three nationalities. In contrast, according to the Japanese Bureau of Immigration Ministry of Justice, 2010 the number and origin of registered foreigners in Japan by the end of 2009 was as shown in Table 2.

This discrepancy mirrors the common lack of awareness about the actual condition of foreign residents in Japan. Although the majority of foreign residents in Japan are of Asian and South American origin, there is a strong tendency to identify the term "foreigner" with a person from "the West".

The following results of Survey A also provide some evidence of this tendency. In response to the question "Do you prefer to communicate in Japanese when talking to a foreigner in Japan?" 63 respondents gave negative answers $(n=220)$. When asked about the reason, 44 of them stated that they regarded communication with foreigners as an opportunity to practice or improve their English. The reasons given by the 154 respondents who answered with "yes" also show this kind of overgeneralization. Here 33 stated they preferred the use of Japanese because they "can't speak English" and 31 because they "only speak Japanese".

In a further question of Survey A, respondents ( $\mathrm{n}=$ 157) who stated that they had frequent or occasional opportunity to communicate with Non-Japanese were asked about the origin of these people and the language they primarily use in communication with these people (Fig. 1).
Table 2: Registered foreigners in Japan by the end of 2009

\begin{tabular}{|c|c|}
\hline Registered foreigners & $2,186,121$ \\
\hline Asian countries: & $\underline{1,688,865}$ \\
\hline 1. China: & 680,518 (Including 44,072 people from Taiwan) \\
\hline 2. South and North Korea: & $\begin{array}{l}578,495 \text { (Amongst them } 416,309 \text { "Old-comers", } \\
\text { people who came to Japan during the Japanese } \\
\text { colonialization and their descendants) }\end{array}$ \\
\hline 3. Philippines: & 211,716 \\
\hline South America: & $\underline{340,857}$ \\
\hline 1. Brazil: & 267,456 \\
\hline 2. Peru: & 57,464 \\
\hline North America: & $\underline{66,876}$ \\
\hline Europe: & $\underline{61,721}$ \\
\hline Oceania: & $\underline{14,179}$ \\
\hline Africa: & $\underline{12,226}$ \\
\hline
\end{tabular}

As the data is based on answers out of interviews and questionnaires and no concrete information is provided concerning the background of the NonJapanese person the respondents were referring to (e.g., permanent resident, tourist), one must be cautious in interpreting this result. Nevertheless, a tendency can be seen that communication with people from Western countries is mainly conducted in English, while with people from Asian countries Japanese is the primarily used language. This finding does not only mirror the correlation between origin of the interlocutor and possibility of communication in English (or attitudes of Japanese people concerning this), it also implies differences in Japanese language ability between the two groups of foreigners. In regard to this point, the respondents ( $\mathrm{n}$ $=$ 157) reported the following experiences concerning the language ability of foreigners they have spoken to in the past (Fig. 2).

As shown in Fig. 2, more than $80 \%$ report that the majority of people from Western countries they have spoken to in Japan spoke only little Japanese or were not able to communicate in Japanese at all.

In this context the question arises, in how far the stereotypical image of a "foreigner" as a person from the West and the perceived lack in Japanese language ability among this minor group of foreigners may impact upon general attitudes of Japanese native speakers regarding their own language. Study A and $\mathrm{B}$ both referred to this point by asking about images connected to the Japanese language. In Study A, 44\% of the respondents $(n=220)$ judged Japanese an "especially difficult language". Compared to Survey $\mathrm{B}$, this percentage is relatively low. Here $67 \%$ of the Japanese students $(n=337)$ regarded Japanese as an especially difficult language. 
Primarily used language of respondents who mainly speak to people from Asian countries

Primarily used language of respondents who mainly speak to people from Western countries

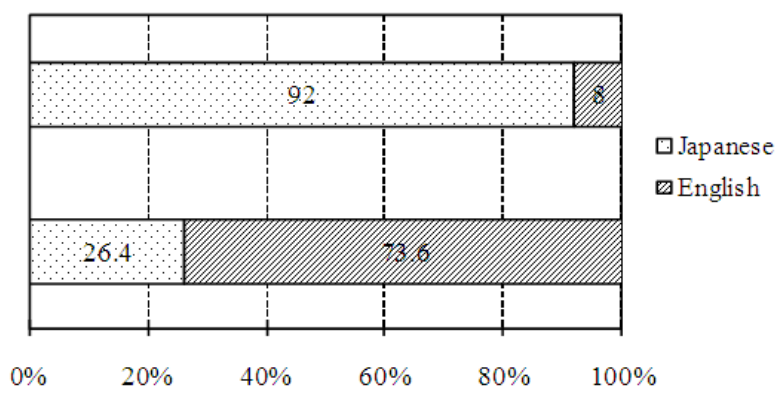

Fig. 1: Relation between origin of the foreigner and primarily used language

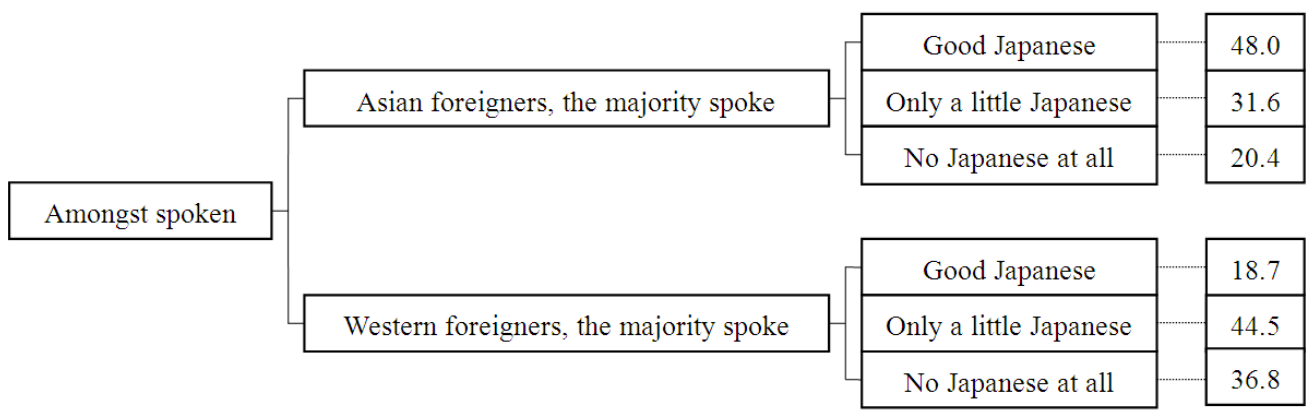

Fig. 2: Experiences regarding language ability of two groups of foreigners (\%)

Table 3: Views regarding the Japanese language

\begin{tabular}{lclr}
\hline 337 Japanese university students (Survey B): & & 349 foreign students from Korea (Otani, 2007): \\
\hline $\begin{array}{lll}\text { The Japanese language is... } \\
\text { an especially difficult language }\end{array}$ & 225 & Learning Japanese is... & very difficult \\
& 100 & difficult & neither easy nor difficult \\
as easy or difficult as any other language & & easy & 114 \\
& 12 & very easy & 129 \\
an especially easy language & & 98 \\
\hline
\end{tabular}

Likewise, in a survey conducted on Japanese nationals by the NHK (Japan Broadcasting Corporation) Broadcasting Culture Research Institute in $1991,79 \%$ of the respondents said Japanese was more difficult for foreigners to learn than other languages (Heinrich and Sugita, 2008). The following survey conducted by Otani (2007) offers interesting data for comparison. Here 349 foreign students from Korea were asked about their views on the Japanese language. While nearly two thirds of the Japanese students in Study B judged their own language as especially difficult, the Korean students interviewed by Otani said just the opposite about the Japanese language (Table 3 ).

In Study B Japanese university students $(\mathrm{n}=191)$ were further asked, which language they would choose for their mother tongue if they had the choice. As a result, about $60 \%$ chose English, 21\% Japanese and $19 \%$ other languages. Interestingly, the fact that about
$80 \%$ of the students chose either English or Japanese coincides with the data of Otani (2007), who carried out a similar research over a span of more than 30 years (1961 1995). When asked for the reason of their choice, the respondents of Study B showed the following clear tendency. English was in general associated with attributes like "international", "global" or "no need to learn other languages", while Japanese was almost exclusively connected with adjectives like "unique", "difficult" or "beautiful".

\section{DISCUSSION}

In modern times, Japan has exclusively focused its interest on the Western world (after World War 2 especially on the USA) while neglecting the neighboring Asian countries and its own domestic minorities (Lee et al., 2006). Buzzwords like "internationalization" or "globalization" are primarily 


\section{J. Social Sci., 8 (1): 109-115, 2012}

used to refer to Japan's interchange with foreign, especially developed countries, by means of use of the English language. As already mentioned above, in most contexts, including education policies and school curricula, "foreign language" simply means "English". As a matter of fact however, the immense amount of time, effort and money that is spent on English language education in Japan bears little relation to the actual need in daily life. For example, regarding intercultural communication inside the country, the results of Survey A imply that "sharing Japanese" with people of various origins and backgrounds should be a more important issue than "English as a lingua franca".

The success of the TOEIC (Test of English for International Communication) is a vivid example of the commercialization of English language education in Japan under the concept of testable, streamlined language abilities, mainly for entrance examinations or job-hunting rather than for the actual personal need. TOEIC was established in 1979 by the American institution ETS (Educational Testing Service) and has since then irresistibly made its way into English language education curricula. According to The Japan Times (McCrostie, 2009), about $80 \%$ of the worldwide 5 million people who paid to be TOEIC-tested in 2008 were from Japan (about 1.7 million) and Korea.

Besides economical based interest in the Western world and the English language, a deep cultural identity crisis after Japan's defeat in World War 2 and the USAmerican occupation can be regarded as another major factor of the one-sided orientation regarding other cultures and languages. Especially in the 70's and 80's this crisis gave rise to a flood of pseudo-scientific literature claiming the "uniqueness" of Japanese culture and language, the so called "Nihonjinron". This literature compared Japanese culture and language exclusively with that of Western countries (especially the USA), which made it possible to create an identity based on emphasizing Japan's "otherness" while maintaining the illusion of homogeneity within the country (Befu, 2001; Burgess, 2004). Education policies such as inviting thousands of "native Englishspeaking" teaching assistants to Japanese schools in order to "internationalize Japan" (JET Programme) (http://www.jetprogramme.org/ for further information and McConnell (2000) for a comprehensive discussion) and the above mentioned "Action Plan to Cultivate Japanese with English Abilities" can only be fully interpreted against this ideological background. By "importing diversity" (McConnell, 2000) and emphasizing a world view based on a clear distinction between "us" and "them" (McVeigh, 2002), these kind of policies succeeded in diverting attention away from domestic multiculturalism and multilingualism and reinforced the observed stereotypes regarding "foreigner", "foreign language" and "intercultural communication".

The data on attitudes regarding the "difficulty" of the Japanese language may also be interpreted from this point of view. In other words, a perceived linguistic imbalance due to a one-sided language education has to be considered an important factor when discussing ethnocentric tendencies in general and linguistic nationalism in particular. In the Japanese context, a correlation between the following two factors can be regarded as playing a crucial role in the development and maintenance of common views and stereotypes concerning the "difficulty" or "learnability" of the Japanese language.

(a) The stereotypical image of a "foreigner" as a person from the West and thus the generalization of the perceived lack in Japanese language ability among this minor group of foreigners.

Survey A showed that the Japanese language ability of people from Western countries is perceived as being comparatively low. In contrast to people from other Asian countries, it seems as no surprise when a Japanese person assumes that with an interlocutor from a Western country there is no, or only very limited, possibility of communication in Japanese. Therefore an increased use of "foreigner talk" (Long, 1992) and various kinds of "overaccommodation" (Ostheider, 2005; 2009) by Japanese native speakers towards this group appear to be based on a common lack of effort in Japanese language acquisition amongst the majority of (even long-term residing) Western foreigners, rather than on linguistic discrimination. The image that people from Western countries have no or only little Japanese language ability is not only based on actual experiences. It is also reinforced by mass-media (e.g., the appearance of "Japanese speaking" Westerners as highlights in Japanese variety shows) and the above mentioned education policies that focus on "native English speakers" as a symbol of a typical "foreigner". In contrast to this, the often observed attitude amongst Japanese people that it is natural to speak in Japanese to people from Asian countries, mirrors the perceived higher language ability of this group on the one hand, but may, on the other hand, also be interpreted as due to a feeling of superiority over other Asian countries. Compared to this, the attitude that one "has to speak in English" towards Western foreigners, which was also salient in other results of Survey A, may in part result from a feeling of inferiority towards Western countries, reinforced by perceived linguistic inequality due to English language imperialism. 


\section{J. Social Sci., 8 (1): 109-115, 2012}

(b) A common one-sided interest in European languages while neglecting more related languages, like e.g., those of domestic minorities or neighboring countries.

From the point of view of linguistic similarity, the effort of a native speaker of Korean studying Japanese is comparable to e.g. that of a native speaker of German studying English. In other words, the Korean students' view of the Japanese language (Table 3) mirrors the relativity of subjective perceptions regarding the "difficulty" of a foreign language. The inclusion of domestic minority languages and languages of neighboring countries in language education has to be considered an essential factor in raising consciousness towards multilingualism and fostering competence in intercultural communication. Korean for example, as a language that is closer related to Japanese than English, might be an adequate language to start with. Not for the purpose of "cultivating Japanese with Korean abilities", but to give young children the necessary background to develop more objective language attitudes towards their own and other languages before getting involved with e.g., English. In the present Japanese environment however, where official education guidelines clearly specify that "other foreign languages have to be treated according to the guidelines on English" MEXT, 2009, it appears rather idealistic to question the status quo of English as coming first in second language education.

\section{CONCLUSION}

An objective self-awareness of the multicultural and multilingual situation inside the country is an important and urgent task for issues concerning language and culture education in Japan. In order to accomplish this task it is indispensable to reconsider common conceptions of "foreign" and "Japanese"; both in terms of languages and their speakers. Languages are used by humans and not by countries. As the case of a Korean descendant in $3^{\text {rd }}$ generation who is a Japanese monolingual speaker or that of a Brazilian migrant of Japanese descent who does not speak Japanese illustrate, language education policies should be based on concepts like "first language", "second language", "heritage language", "community language", "language for communication in a multilingual setting". rather than on "national" and "foreign".

This requires also an awareness of the growing importance of the Japanese language as a language of intercultural communication. Education policies still make a clear distinction between "Japanese language education", which is used in the context of second language education and "National Language education", which refers to first language education
(Coulmas, 2007). In curriculum guidelines of the Ministry of Education only the latter is referred to, specifying the following aim: "Fostering an attitude of respect for the National Language" MEXT, 2009. Fostering the ability to share the language should also be an important aim, as it is without doubt a decisive challenge regarding further development inside the country as well as Japan's future role in the Asian region.

If all humans are equal, so are their languages. It goes without saying that this idealistic view bears little relation to the reality of language choice and language education in human society. But, even though it might be unattainable, it still remains the most important challenge of language policy. Language education policies that are restricted to the "National Language" and English, neglect this challenge. As it was apparent from the data presented in this study, they reinforce linguistic nationalism and produce language attitudes that justify linguistic and racial discrimination. Language attitudes like "if you are born a native English speaker, it is fine to be monolingual" are not adequate for a multilingual society like Japan and language education policies should be aware of this.

\section{REFERENCES}

Befu, H., 2001. Hegemony of Homogeneity: An Anthropological Analysis of "Nihonjinron". 1st Edn., Trans Pacific Press, Melbourne, ISBN: 1876843055, pp: 181.

Burgess, C., 2004. Maintaining identities: Discourses of homogeneity in a rapidly globalizing Japan. Electr. J. Contemporary Japanese Stud.

Coulmas, F., 2007. Language Regimes in Transformation: Future Prospects for German and Japanese in Science, Economy and Politics. 1st Edn., Walter de Gruyter, Berlin New York, ISBN: 311019158X, pp: 216.

Heinrich, P. and Y. Sugita, 2008. Japanese as Foreign Language in the Age of Globalization. 1st Edn., Iudicium Verlag, Munchen, ISBN: 3891298544, pp: 266.

Lee, S., S. Murphy-Shigematsu and H. Befu, 2006. Japan's Diversity Dilemmas: Ethnicity, Citizenship and Education. 1st Edn., iUniverse, New York, ISBN: 0595362575, pp: 280.

Long, D., 1992. Nihongo ni yoru komyunikēshon: Nihongo ni okeru forinā-tōku wo chūshin ni [Communication in Japanese: Focusing on Japanese foreigner talk]. Nihongogaku, 11: 24-32.

McConnell, D.L., 2000. Importing Diversity: Inside Japan's JET Program. 1st Edn., University of California Press, Berkeley, ISBN: 0520216369, pp: 328 . 
McCrostie, J., 2009. TOEIC no turkey at 30. The Japan Times Online.

McVeigh, B.J., 2002. Self-Orientalism Through Occidentalism: How "English" and "Foreigners" Nationalize Japanese Students. In: Japanese Higher Education as Myth, McVeigh, B.J., (Ed.). M.E. Sharpe, Armonk, ISBN-10: 076560924X, pp: 148179.

Ostheider, T., 2005. "Kīta no ha kochira na no ni”": Gaikokujin to shintaishōgaisha ni taisuru daisanshahentō wo megutte ["3rd person response as a form of overaccommodation: An example of inappropriate communication behaviour towards foreign and physically handicapped people]. Japanese J. Language Soc., 7(2): 39-49.
Ostheider, T., 2009. "Communication With Foreigners" in Japan: Image and Reality. In: Plurilinguismo, Multiculturalismo, Apprendimento delle Lingue. Confronto Tra Giappone E Italia, Ferreri, S. (Ed.). Sette Citta, Viterbo, pp: 229-248.

Otani, Y., 2007. Nihonjin ni totte Eigo to ha Nani ka [What English Means to Japanese People]. Taishukan Shoten.

Sugino, T., 2007. Nikkei Brazilians at a Brazilian School in Japan: Factors Affecting Language Decisions and Education. 1st Edn., Temple University, ISBN-10: 054937194X, pp: 294. 